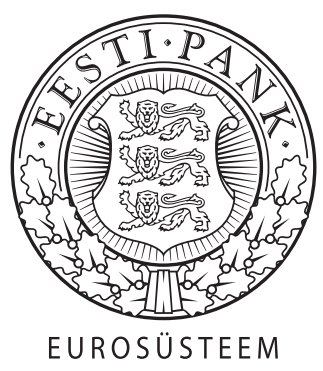

\title{
Uncovered Interest Parity in Central and Eastern Europe: Expectations and Structural Breaks
}

Juan Carlos Cuestas, Fabio Filipozzi, Karsten Staehr 
The Working Paper is available on the Eesti Pank web site at: http://www.eestipank.ee/en/publications/series/working-papers

For information about subscription call: +372 668 0998; Fax: +372 6680954 e-mail: publications@eestipank.ee

ISBN 978-9949-493-57-9 (hard copy)

ISBN 978-9949-493-58-6 (pdf)

Eesti Pank. Working Paper Series, ISSN 1406-7161; 4/2015 


\title{
Uncovered Interest Parity in Central and Eastern Europe: Expectations and Structural Breaks
}

\author{
Juan Carlos Cuestas, Fabio Filipozzi and Karsten Staehr
}

\begin{abstract}
This paper examines the empirical validity of the hypothesis of uncovered interest parity (UIP) using data from five Central and Eastern European countries with floating exchange rates for the period 2003-2014. The analysis includes forward-looking as well as static expectations and also allows for different types of structural breaks. The variable representing the deviation from UIP is stationary when expectations are forward-looking, ruling out persistent divergences from UIP. The deviation from UIP is however typically not stationary when expectations are static, even when structural breaks are incorporated, and this leads to the rejection of the UIP hypothesis in this case. The results underscore the importance of the expectations assumptions when the UIP hypothesis is tested.
\end{abstract}

JEL Codes: C32, F15

Keywords: uncovered interest parity, carry trade, expectations, structural breaks, Central and Eastern Europe

Corresponding author's e-mail address: j.cuestas@sheffield.ac.uk

The views expressed are those of the authors and do not necessarily represent the official views of Eesti Pank or the Eurosystem. 


\section{Non-technical summary}

The hypothesis of uncovered interest parity posits that the expected returns of investments in assets that are denominated in different currencies but otherwise similar should be equal. This paper examines the empirical validity of this hypothesis using data from five CEE countries for the period 19992013. The five countries, Croatia, the Czech Republic, Hungary, Poland and Romania, are among the largest economies in Central and Eastern Europe and all operated floating exchange rate regimes during the sample period.

The empirical investigation analyses the time series properties of the deviation from uncovered interest parity for investment with a horizon of one month. A persistent deviation would suggest that carry trades would be expected to be profitable, while this would not be the case if the deviation is stationary. Two important innovations are introduced in this paper. First, we consider two different assumptions about the formation of expectations, i.e. rational expectations and static expectations. Second, we allow for structural breaks so as to analyse the evolution of persistence of shocks after and before some endogenously determined dates.

A number of interesting results come out of the empirical analyses. When expectations are assumed to be forward-looking or rational, we find for the five CEE countries that there are not persistent deviations from uncovered interest parity, except a possible constant term. This means that an investor cannot use a deviation from uncovered interest parity as an indication that the deviation will persistent the following month. In other words, an investor should not expect to earn a greater risk-adjusted return from investment in assets denominated in one or the other currency.

When expectations are assumed to be static, the deviation from uncovered interest parity is found to exhibit a unit root for at least part of the time sample for all five countries. There seem, however, to be structural breaks in the unit processes either at the beginning of the sample or during the global financial crisis due to disturbance. The beginning of the sample exhibits interest rate convergence for several of the CEE countries, while the period around the global financial crisis saw very substantial disturbance of interest and exchange markets in the sample countries. The lack of empirical support for the UIP hypothesis in this case may suggest the presence of arbitrage possibilities for an investor with static expectations. The observed presence of carry trade may thus be tied to investors having static or non-rational expectations.

The overall conclusion from this study is that expectations are of prime importance for the results when the UIP hypothesis is tested empirically. In the sample of CEE countries used in this paper, the assumption of forward- 
looking or rational expectations implies that the hypothesis of UIP cannot be rejected, while the assumption of static expectations generally means that the UIP hypothesis cannot be upheld in most parts of the sample period. These results clearly underscore the importance of the assumptions regarding the expectation when the UIP hypothesis is tested, but also suggest the pertinence of studies of the formation of expectations in foreign exchange and interest markets. 


\section{Contents}

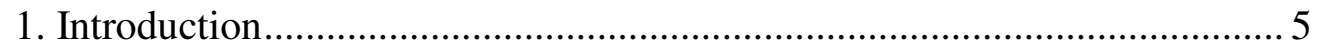

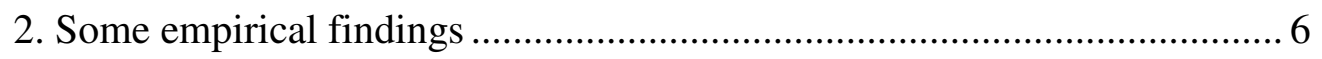

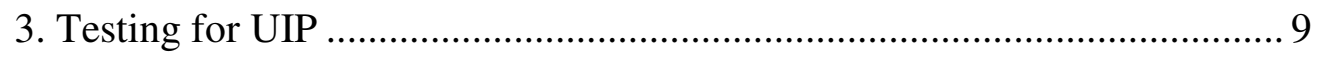

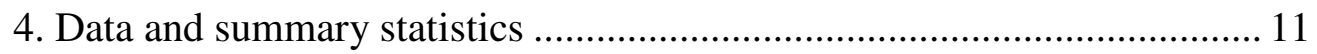

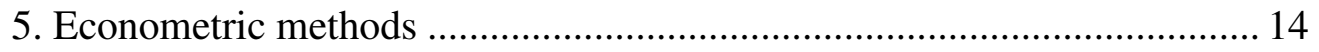

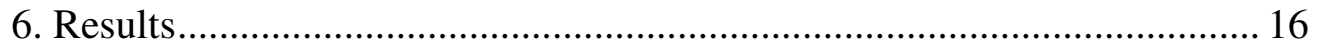

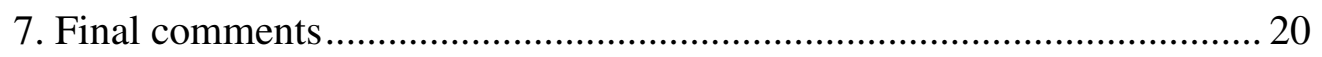

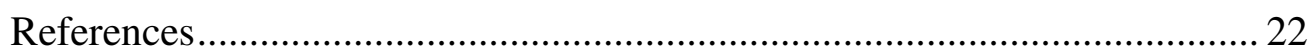




\section{Introduction}

The hypothesis of uncovered interest parity (UIP) is the theoretical cornerstone in international finance and open economy macroeconomics. The hypothesis rests on the idea that arbitrage leads to equalisation of the return on assets denominated in the domestic currency and the expected return on comparable assets denominated in foreign currencies. If the UIP hypothesis holds, returns across different financial markets and different currencies are tied together. In this way UIP epitomises the key constraints in international financial markets faced by investors, borrowers and policymakers (De Grauwe (2014), Engel (2014)).

Testing of the UIP hypothesis is also important for scientific or conceptual reasons. The hypothesis builds on the conception that all gains from trade are exhausted, meaning that exchange and interest rate markets function efficiently. Divergence between domestic and expected foreign returns may suggest, however, that "imperfections", such as transaction costs, different risk profiles and non-symmetric tax treatments play an important role. Empirical testing of the UIP hypothesis may provide information on the functioning of financial markets.

This paper provides econometric analyses in which the UIP hypothesis is tested on data from five countries with floating exchange rates from Central and Eastern Europe (CEE): Poland, the Czech Republic, Hungary, Romania and Croatia. The data sample ranges from September 2003 to December 2013 and includes periods in which the countries experienced rapid economic growth, increasing integration and the fallout from the global financial crisis. As discussed in the literature survey in Section 2 there are only a few studies that examine the empirical validity of the UIP hypothesis for the CEE countries, particularly studies that use data covering the period of EU accession and the global financial crisis.

The CEE countries liberalised their capital markets and removed the remaining exchange rate restrictions before joining the EU. Many of the countries experienced substantial capital inflows in the years immediately before and after the accession to the EU, just to experience reversals following the global financial crisis in 2008-2009 (Jevcak et al. (2010)). The question of whether these abrupt changes in capital flows have affected the relationship between exchange rates and interest rates in the CEE countries is largely unresearched.

Testing the UIP hypothesis for the CEE countries is also important because households and firms in many countries in the region have borrowed extensively in foreign currencies, mainly the euro (Rosenberg and Tirpak (2008)). This would suggest that borrowers expect that borrowing in a for- 
eign currency will be cheaper than borrowing in the domestic currency, meaning they have made the bet that UIP will not hold within the horizon of the loan. Speculators without an underlying motive of borrowing or saving have similarly taken positions in the currencies of the CEE countries through carry trade. Rosenberg and Tirpak (2008) and Brzoza-Brzezina et al. (2010) find that the interest differential between domestic and foreign rates is an important determinant of borrowing and saving in foreign currencies in the CEE countries. ${ }^{1}$

This paper contributes to the empirical literature investigating the empirical validity of UIP in a number of ways. First, the sample considers the CEE countries with a floating exchange rate during a decade in which the world economy was affected by numerous shocks. Second, the global financial crisis and the subsequent instability may have changed economic relationships fundamentally, and the empirical methods therefore allow for structural breaks and determine these endogenously. Finally, given the weak support for the UIP hypothesis in different datasets, the importance of expectations arises; different specifications of the expectations for future exchange rate changes are assessed to address this issue.

The rest of the paper is organised as follows: Section 2 surveys a number of empirical studies with a particular emphasis on the CEE countries. Section 3 discusses the theoretical foundation of the UIP hypothesis and how to test it empirically. Section 4 documents the data. Section 5 presents the econometric methods used. Section 6 shows the results of the estimations and provides some interpretations. Finally, Section 7 summarises the results.

\section{Some empirical findings}

Uncovered interest parity has generally been rejected in empirical studies. Even more puzzling, many studies have found that currencies offering higher interest rates tend to appreciate against currencies yielding lower interest rates, creating the forward premium anomaly. These findings have been explained in different ways.

One of the first influential contributions on UIP was Meese and Rogoff (1983). The authors found that the interest rate differential has no predictive

\footnotetext{
${ }^{1}$ Batini and Dowling (2011) use a UIP framework to decompose exchange rate movements between the US dollar and major currencies into shocks stemming from US monetary policy and other sources. The sharp depreciation of most of the sample currencies against the US dollar during the global financial crisis cannot be attributed to changes in the interest rate differential, but rather to changes in the risk premia. The subsequent appreciation of many of the currencies may partly reflect the carry trade exploiting low US interest rates and higher interest rates in other countries. No CEE countries are included in the sample.
} 
power on exchange rate movements. This result, together with the forward premium anomaly, has been documented in many subsequent studies including Booth and Longworth (1986), Froot and Thaler (1990), Engel (1996) and Alexius (2001).

There have been many attempts to explain empirically the puzzle posed by the failure of UIP in most empirical studies. UIP has been tested on a longer time horizon. Usually this is done with monthly or quarterly data, while some contributions, including Chinn and Meredith (2004), Mehl and Cappiello (2007), Sarmidi et al. (2011), have found that UIP is not empirically rejected at horizons of 5 or 10 years.

The presence of different interest rate regimes has been suggested as an alternative explanation for the rejection of UIP. In particular when the interest rate differentials are large, arbitrage becomes more compelling and UIP is more likely to hold, while arbitrage is less compelling when interest rate differentials are low (Froot and Thaler (1990), Lothian and Wu (2011)). This also explains why UIP is less likely to be rejected in empirical studies of emerging markets, where both inflation and interest rates tend to be higher than for high income countries (Alper et al. (2009), Bansal and Dahlquist (2000)).

In recent years more attention has been dedicated to the problem of expectation formation. When UIP is testing, it is usually assumed that expectations are rational, i.e. that the expected or forecast exchange rate for the end of the contract horizon is equal to the realised exchange rate plus an error term that is independent of all information available at the time of the contract entry. In practice this means that the expected nominal exchange rate is replaced by the realised exchange rate. From an economics viewpoint it is an obvious thought that rejections of UIP may be the result of this very restrictive assumption. From an econometrics viewpoint the assumption implies that the expected exchange rate becomes extremely volatile as this is a case of a realised exchange rate. Typically these fluctuations in the expected exchange rate completely dominate possible differences in the interest rates.

Ter Ellen et al. (2013) test different expectation formation specifications in foreign exchange markets and find that interest rate differentials are used as a carry trade strategy in the short term horizon (causing the forward premium anomaly), but are used according to the UIP prescription in the long horizon. Felcser and Vonnak (2014) similarly find that carry trade behaviour explains the relation between interest rate differentials and the exchange rate in the short term, but not in the longer term. Both contributions suggest that short-term expectations are not based on the interest rate differential. Lothian and $\mathrm{Wu}$ (2011) also look at expectations and analyse a sample that spans over two centuries, finding that UIP rejection can be attributed to the slow adjust- 
ment of expectations. All these contributions show that the way in which expectations are modelled is crucial in the empirical test of UIP.

Another aspect of the UIP literature that is relevant for our research is the presence of structural breaks, which can cause the arbitrage condition to be rejected. This problem has been studied particularly in emerging markets, where structural breaks and regime shifts can be more frequent. Volatility and volatility regime changes have been linked to different macroeconomic variables in some contributions. Goh et al. (2006) analyse a sample from Malaysia using a Switching ARCH model, and they show that different volatility regimes are important in explaining UIP deviation dynamics. Li et al. (2013) find that UIP does not hold because of nonlinearities in the relationship of interest rates and exchange rates, and UIP tends to hold in higher volatility regimes. The different volatility regimes are identified endogenously using STR (smooth transition regression) models. Baillie and Cho (2014) analyse explicitly the presence of structural breaks in the forward premium anomaly for eight developed market currencies against the USD, using different methods (rolling regressions, Bayesian estimations and the Time Varying Parameter method) and find the presence of four to five breaks on a 23-year sample. For some of the currencies the forward premium disappears after the recent global financial crisis.

Only a few studies have tested the empirical validity of UIP for countries from Central and Eastern Europe. Jiang et al. (2013) test UIP using data from $10 \mathrm{CEE}$ countries and apply nonlinear threshold tests, and find that, after accounting for nonlinearities and non-stationarity, UIP is confirmed for seven of the countries analysed. It is noticeable that most of the other studies reject UIP. Triandafil and Richter (2012) test UIP for five CEE countries and find that inflation dynamics help explain departures from UIP.

Holtenmöller (2005) also stresses the importance of the risk premia due to economic convergence/divergence in the violation of UIP for CEE countries. Filipozzi and Staehr (2012) find for five CEE countries with a floating exchange rate regime that UIP is broadly rejected and that global risk aversion indicators are important in explaining the rejection of UIP. Braili and Sitzia (2003) use panel data and find that the deviations from UIP are nonlinear and that factors linked to the risk premium can explain deviations from UIP. Hoffmann (2012) confirms the rejection of UIP for 10 CEE countries, and finds that this is due to capital flows driven by carry trade.

In summary, evidence on UIP is extremely mixed, with results in favour or against the hypothesis depending on countries, samples and the methods employed. The uncertainty about the empirical validity of UIP is also a characteristic of the few studies focused on the CEE countries. 


\section{Testing for UIP}

In this section we discuss the theory behind Uncovered Interest Parity and ways to test the hypothesis.

The theory of UIP is based on a simple arbitrage assumption, i.e. that investments in assets denominated in different currencies should yield the same expected returns (Levi (2005), Ch. 8). At time $t$ an investor with an investment horizon of one period is assumed to face two different investment possibilities. $^{2}$ The first possibility is to invest in an asset denominated in the local currency and with a fixed interest rate $i_{t}$. The interest rate is the return per period and it is known at time $t$ and is fixed over the investment horizon of one period. The gross return of this investment possibility is $\left(1+i_{t}\right)$.

The other possibility is to invest in an asset denominated in foreign currency but with otherwise similar characteristics. In this case the investor will exchange the initial investment amount at the exchange rate $S_{t}$, and invest the sum in the foreign denominated financial instrument bearing a fixed interest rate of $i_{t}^{*}$ per period. The total return of the investment in foreign currency will be $\left(1+i_{t}^{*}\right) / S_{t}$. This sum must be converted back into the local currency at the exchange rate $S_{t+1}$ prevailing at the end of period $t+1$.

When the investment decision is taken at time $t$, the exchange rate prevailing at $t+1$ is not known so the investment decision must depend on the investor's expectations of the exchange rate at $t+1$, which we label $S_{t+1}^{e}$. The baseline assumption in the literature is that the investor is risk neutral, in which case the investor will be indifferent between the two different investment possibilities as long as their expected returns are identical:

$$
\left(1+i_{t}\right)=\left(1+i_{t}^{*}\right) \frac{S_{t+1}^{e}}{S_{t}}
$$

Eq. (1) represents the Uncovered Interest Parity condition. By taking logs, using the approximations $i_{t} \approx \log \left(1+i_{t}\right)$ and $i_{t}^{*} \approx \log \left(1+i_{t}^{*}\right)$ and denoting the logarithms of the exchange rate variables with lowercase letters, $s_{t}=\log \left(S_{t}\right)$ and $s_{t+m}^{e}=\log \left(S_{t+m}^{e}\right)$, the $\log$-linearised version takes the form:

$$
s_{t+1}^{e}-s_{t}=i_{t}-i_{t}^{*}
$$

The left-hand side of eq. (2) is positive when the local currency is expected to depreciate against the foreign currency, bringing an excepted capital gain for the investor from the foreign currency investment. UIP will hold

\footnotetext{
${ }^{2}$ The discussion can easily be adapted to longer investment horizons than one period, but the present example corresponds to the empirical testing in Section 6.
} 
when the expected capital gain is equal to the interest rate differential, the right hand side of eq. (2).

Eq. (2) can be tested empirically in a number of ways. Methods entailing the estimation of a constant and a slope coefficient of the interest rate differential generally yield results that are difficult to interpret. We analyse instead the time series properties of deviations from eq. (2):

$$
d U I P_{t}=\left(i_{t}-i_{t}^{*}\right)-\left(s_{t+1}^{e}-s_{t}\right)
$$

The variable $d U I P_{t}$ denotes the deviation from UIP at time $t$ for a trading horizon of one period.

The empirical testing of UIP rests on the time series properties of the deviation variable $d U I P_{t}$ in eq. (3). If the strict version of the UIP hypothesis holds, then the variable $d U I P_{t}$ should be zero or revert to zero quickly. Persistent deviation might be interpreted as reflecting a risk and liquidity premium or another departure from strict UIP. A persistent positive deviation would mean that the return $i_{t}$ on assets denominated in domestic currency would be higher than the expected return $i_{t}^{*}-\left(s_{t+1}^{e}-s_{t}\right)$ on assets denominated in the foreign currency. In this case there would be a positive expected return from carry trades funded by borrowing in the foreign currency and investing in the domestic currency.

The empirical validity of the UIP hypothesis is assessed by analysing the time series properties of the deviations $d U I P_{t+1}$ given in eq. (3). A stationary process would allow for a constant risk premium, but shocks in the process would only have a temporary effect on $d U I P_{t+1}$ in which case we would conclude that UIP is satisfied. If the process exhibits a unit root, shocks would be persistent and a deviation from UIP would be persistent, in which case there is no support to the UIP hypothesis.

Tests of the time series properties of the deviation from UIP has also been used in other studies examining the efficiency of foreign exchange markets, including Brunnermeier et al. (2008), Hoffmann (2012) and Holtenmöller (2005). Another methodology entails the estimation of a cointegrating relationship between interest rates and the expected exchange rate depreciation. This method is problematic if all variables are not integrated of order one and also complicates testing for structural breaks. The unit root tests in this paper are equivalent to testing for cointegration in a model where the cointegrating vector is given by the UIP hypothesis. 


\section{Data and summary statistics}

This section documents the data used in the empirical analyses for the five sample countries, Croatia, the Czech Republic, Hungary, Poland and Romania. Data are monthly and the UIP hypothesis is tested for a trading horizon of one month. The data are from Ecowin.

The interest rates are the one-month interbank offered interest rate in the five CEE countries and the one-month Euribor rate. ${ }^{3}$ Interest rates on the interbank market are chosen as they would be close to those at which an institutional investor could borrow or lend at the rather short horizon of one month. The interest rates are expressed in terms of return per month by simply dividing the annual return by 12 . The exchange rates are denominated in units of local currency per euro. ${ }^{4}$

The interest rate differential is computed as the difference between the one-month interbank interest rate in the CEE country and the one-month Euribor rate, both taken at the last trading day of the previous month. The interest rate differential is the monthly return differential due to the way the interest rates are defined.

The one-month expected depreciation requires data on the spot exchange rate and on the expected exchange rate one month ahead. The exchange rates are taken at the end of the month. We use two different assumptions for the expectation of the exchange rate one month ahead.

- Rational expectations (RE) mean that there will be no systematic difference between the expected and the realised exchange rate, i.e. the difference should have zero mean and be serially uncorrelated. This implies that the realised exchange rate at the last trading day of the month can be used as the expected exchange rate for the month.

- Static expectations (SE) entail that the expectation for the exchange rate one month ahead is the same as the present exchange rate. This means that the expected exchange rate depreciation is always zero. ${ }^{5}$

The deviation from uncovered interest parity, $d \mathrm{UIP}$, is calculated using eq. (3). If expectations are rational (RE), $d$ UIP is the interest rate differential minus the exchange rate depreciation. If expectations are static (SE), the deviation is simply the interest rate differential. Table 1 shows the mean and standard deviation of the deviation from UIP with rational and static expecta-

\footnotetext{
${ }^{3}$ Ecowin codes: hkr36036, czk14201, huf14201, pln14201, rol36001, deu14101.

${ }^{4}$ Ecowin codes: hrk19400, czk19400, huf19400, pln19400, rol19400.

${ }^{5}$ This assumption would be consistent with the finding in Meese and Rogoff (1983) that standard macroeconomic variables do not help explain developments in the future exchange rate and the best forecast of future exchange realisations is therefore a random walk.
} 
tions. The sample for $d$ UIP starts in March 1999 and ends in October 2014, except for Croatia for which data start in April 2006.

Table 1: Summary statistics for deviation from UIP $\left(d U I P_{t}\right)$

\begin{tabular}{lcccc}
\hline & \multicolumn{2}{c}{ Rational Expectations (RE) } & \multicolumn{2}{c}{ Static Expectations (SE) } \\
\hline Mean & St. dev. & Mean & St. dev. \\
\hline Croatia & 0.106 & 0.699 & 0.150 & 0.243 \\
Hungary & 0.179 & 1.676 & 0.027 & 0.090 \\
Poland & 1.309 & 7.575 & 0.498 & 0.208 \\
Romania & 0.378 & 2.806 & 0.399 & 0.340 \\
\hline
\end{tabular}

Note: Data start in 2006:04 for Croatia and in 1999:03 for the other countries; data end in all cases in 2014:10. The numbers represent the deviation from UIP in per cent per month.

The mean deviation from UIP is positive in all cases but only statistically significant in the case of Hungary with static expectations. There are clear differences in the standard deviations across the two definitions. The standard deviations are much higher for the RE definition than for the SE definition, which is explained by the fact that the deviation from UIP with SE is simply the interest rate differential and interest rates are much smoother than exchange rates changes.

To illustrate the very different volatilities resulting from the two specifications of exchange rate expectations, Figure 1 shows the deviation from UIP with RE and SE for each of the five sample countries. The deviation with RE is extremely volatile in almost all cases. The deviation with RE, i.e. the interest rate differential, is on the other hand relatively smooth and slow-moving for all five countries in the sample. 
(a) Croatia

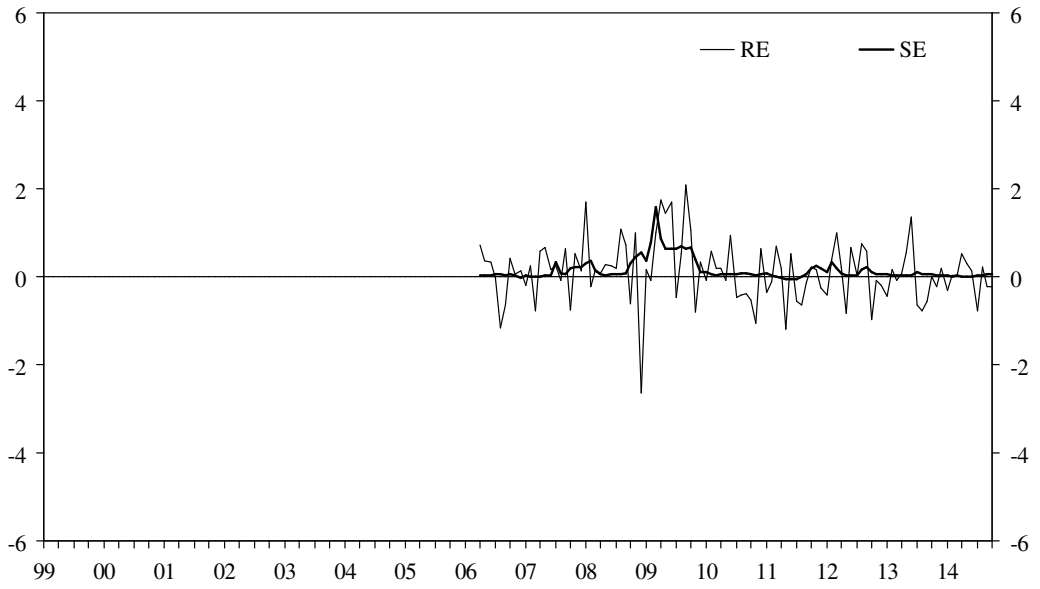

(b) Czech Rep.

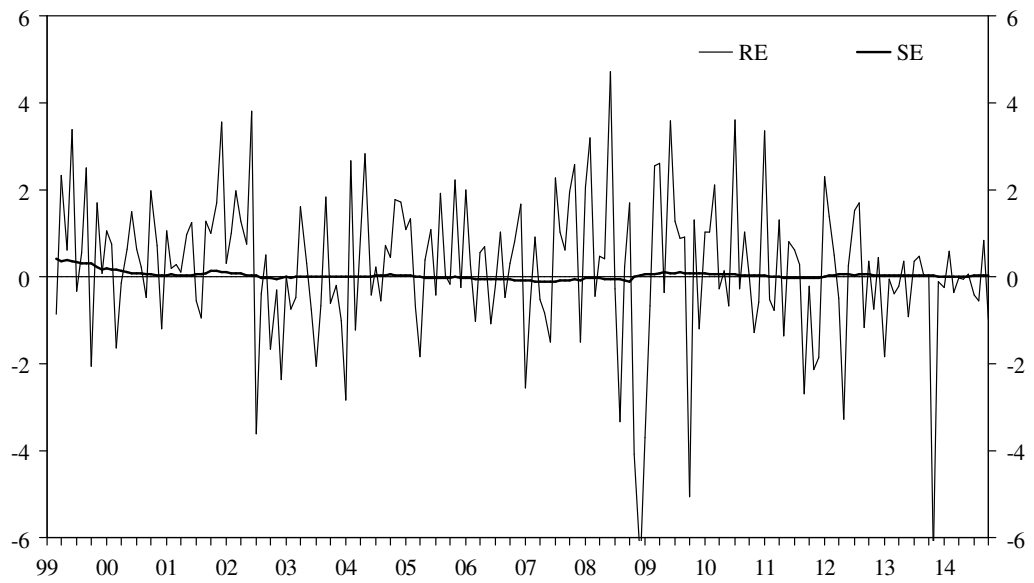

(c) Hungary

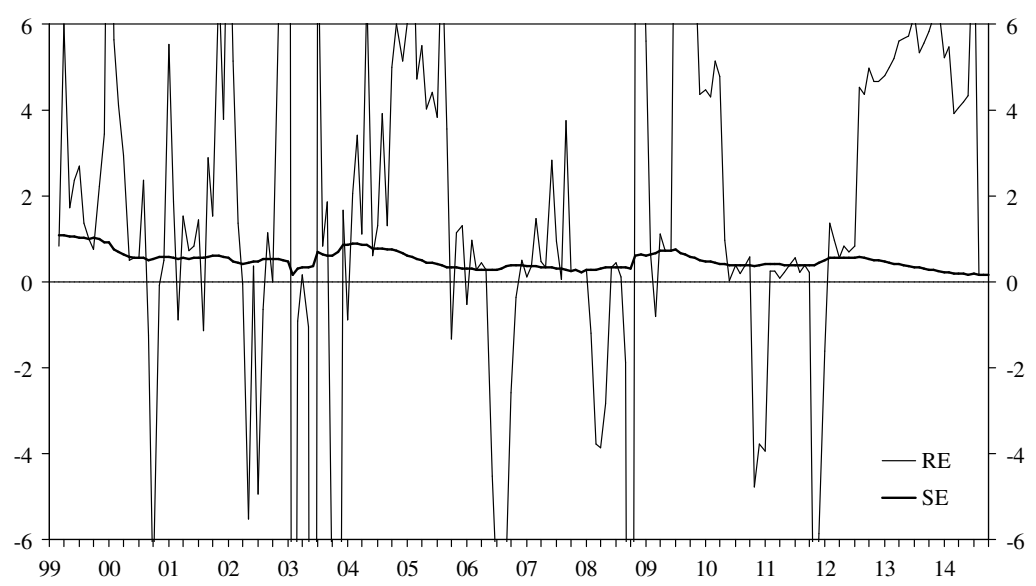

Figure 1: Deviation from UIP $\left(d U I P_{t}\right)$, monthly data 1999:02-2014:10 
(d) Poland

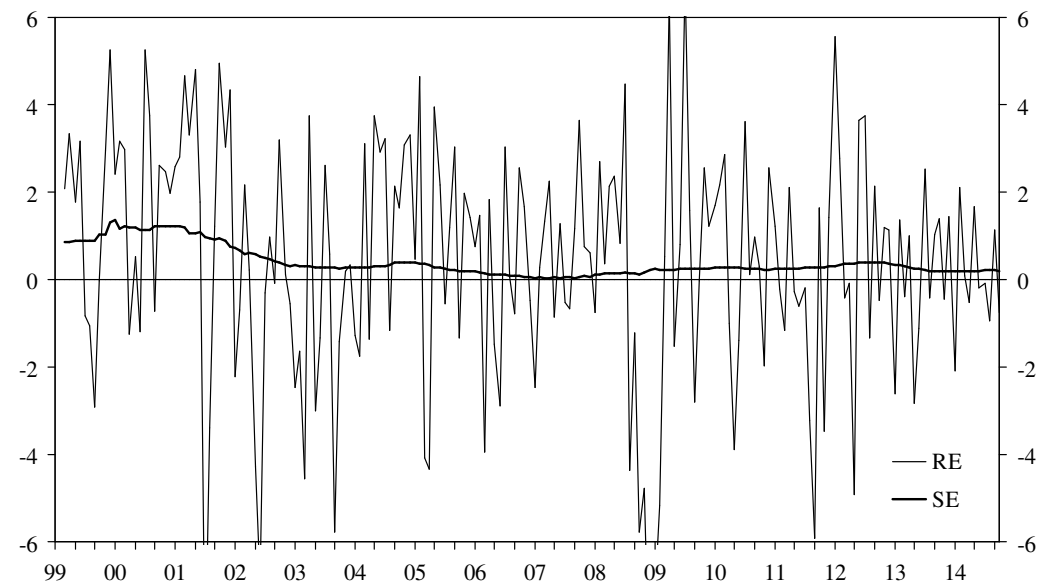

(e) Romania

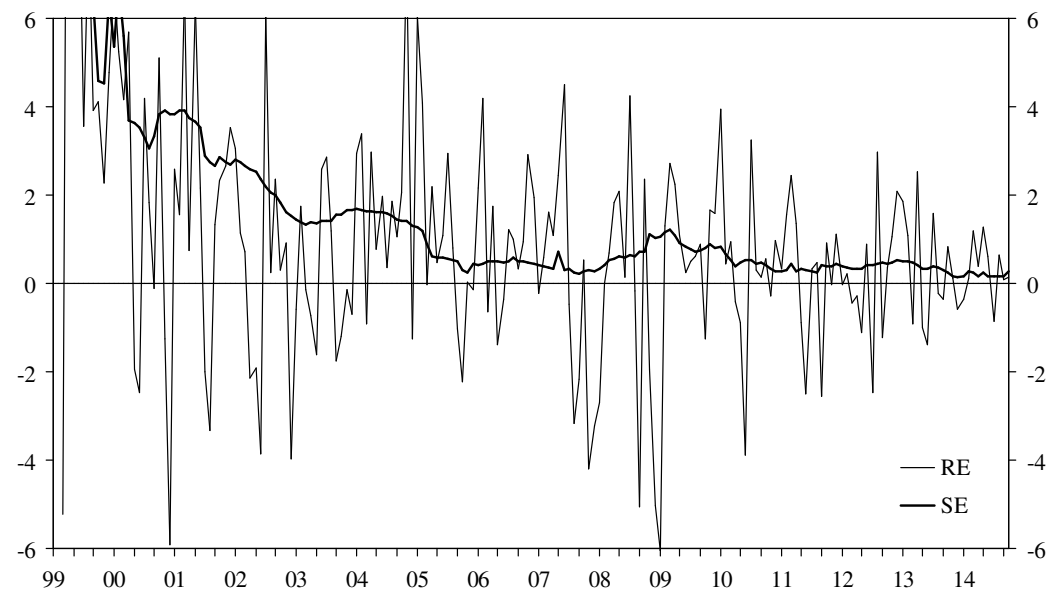

Figure 1: Deviation from UIP $\left(d U I P_{t}\right)$, monthly data 1999:02-2014:10 (cont.)

\section{Econometric methods}

This section discusses the methods we use to analyse the degree of time series properties in the process $d U I P_{t}$, i.e. the deviations from the UIP as defined in eq. (3). We apply a number of unit root tests without and with breaks, and the Bai and Perron (2003) method, which allows us to estimate equations incorporating endogenously determined breaks in $d U I P_{t}$ processes.

First, we apply standard unit root tests. The Ng and Perron (2001) unit root test is a modified version of previously existing tests, incorporating a GLS detrending method and a modified information criterion for the lag 
length selection. The Lee and Strazicich (2003) (LS) test incorporates breaks in the deterministic components.

The Ng-Perron and the LS tests do not make it possible to test for changes in the degree of persistence of the shocks and also not to determine endogenously the break points. Given our interest in analysing the effect of the 2008 crisis on the UIP relationship, we apply the Leybourne et al. (2007) (LKT) unit root test, which allows us to test for breaks in both the deterministic component and in the order of integration from I(1) to $\mathrm{I}(0)$ and vice versa, and to obtain endogenously the break points.

Leybourne et al. (2007) propose a method which uses a Dickey-Fuller type equation as an auxiliary regression, with a Generalised Least Square (GLS) method to detrend the series. The detrended series $y_{t}^{d}$ is computed as $y_{t}^{d}=y_{t}-z_{t}^{\prime} \hat{\beta}$, where $\hat{\beta}$ is the OLS estimator obtained by regressing $y_{\lambda, \tau} \equiv\left[y_{\lambda, T}, y_{\lambda, T+1}-\bar{\alpha} y_{\lambda, T}, \ldots, y_{\lambda, T}, y_{\lambda, T}-\bar{\alpha} y_{\lambda, T-1}\right]^{\prime} \quad$ on $Z_{\lambda, \tau} \equiv\left[z_{\lambda, T}, z_{\lambda, T+1}-\bar{\alpha} z_{\lambda, T}, \ldots, z_{\lambda, T}, z_{\lambda, T}-\bar{\alpha} z_{\lambda, T-1}\right]^{\prime}$ with $\bar{\alpha}=1+\bar{c} / T$ for some $\bar{c}<0, y_{t}=d_{t}+u_{t}$ and $u_{t}=\phi u_{t-1}+\varepsilon_{t}$, i.e. $y_{t}$ is an $\operatorname{AR}(1)$ with or without deterministic components, $d_{t}$ (a constant or, alternatively, a constant and a linear trend). The test statistic is:

$$
M=\inf _{\lambda \in(0,1)} \inf _{\tau \in(\lambda, 1)} \mathrm{DF}_{G}(\lambda, \tau)
$$

which is based upon the following regression:

$$
\Delta y_{t-1}^{d}=\hat{\rho} y_{t-1}^{d}+\hat{\varepsilon}_{t}
$$

where $t=\lambda T, \lambda T+1, \ldots, \tau T$ with $\lambda \in(0,1), \tau \in(\lambda, 1)$. It follows that the test statistic $M$ is computed as the minimum of the double-recursive sequence [ $\operatorname{DF}_{G}(\lambda, \tau), \lambda \in(0,1)$ and $\left.\tau \in(\lambda, 1)\right]$.

Numerous economic and financial disruptions in the sample period suggest that structural breaks are probable. We therefore use the Bai and Perron (2003) method to assess changes in the persistence of shocks. The method allows us to determine the number of breaks and to estimate the relationships for each of the subsamples formed by the endogenously determined breakpoints. The Bai and Perron (2003) method is based on the estimation of the following relationship:

$$
Y=X \beta+\bar{Z} \delta+U
$$

The vectors $\beta$ and $\delta$ contain parameters, $Y$ and $X$ are vectors of time series variables, $U$ is a vector containing residuals, $\delta=\left(\delta_{1}^{\prime}, \delta_{2}^{\prime}, \ldots, \delta_{m+1}^{\prime}\right)^{\prime}$ and $\bar{Z}$ is the matrix which diagonally partitions the full set of observations $Z$ at the breakpoints $T_{1}, \ldots, T_{m}, \bar{Z}=\operatorname{diag}\left(Z_{1}, \ldots, Z_{m+1}\right)$ with $Z_{i}=\left(z_{T_{i-1}+1}, \ldots, z_{T_{i}}\right)^{\prime}$. The 
break points are obtained by means of first estimating $\beta$ and $\delta_{i}$, minimising the sum of the squared residuals $S=(Y-X \beta+\bar{Z} \delta)^{\prime}(Y-X \beta+\bar{Z} \delta)$ for each potential partition, and then finding the breakpoints which minimise the sum of the squared residuals summed across the partitions, i.e. $\arg \min _{T_{1}, \ldots, T_{m}} S_{T}\left(T_{1}, \ldots, T_{m}\right)$.

Bai and Perron (2003) propose the use of three different methods for computing the number of potential breaks, $k$. One method is to choose the number of breaks using the Bayesian Information Criterion (BIC). An alternative method is to use the modified Schwarz criterion proposed by Liu et al. (1997) (LWZ). Finally, it is possible to use either one of two sequential methods, i.e. the null of 0 breaks vs. the alternative of $k$ breaks, and the null of $k-1$ breaks vs. the alternative of $k$ breaks. These later F-type tests are developed in Bai and Perron (1998).

\section{Results}

This section presents the results of the econometric analyses. The analyses are carried out for each of the assumptions on the formation of expectations, i.e. rational expectations (RE) and static expectations (SE).

Table 2 shows the results of the $\mathrm{Ng}$ and Perron (2001) unit root test for the full sample and for the sample after 2008:1, the Lee and Strazicich (2003) (LS) test with two changes in the drift, and the Leybourne et al. (2007) (LKT) test for changes in persistence for endogenously determined dates.

Table 2: Unit root tests results

\begin{tabular}{lcccc}
\hline & Ng-Perron & $\begin{array}{c}\text { Ng-Perron, } \\
\text { crisis sample }^{\text {a }}\end{array}$ & $\begin{array}{c}\text { LS structural breaks } \\
\text { for I(0) }\end{array}$ & $\begin{array}{c}\text { LKT interval with } \\
\text { I(0) }\end{array}$ \\
\hline Czech Rep. (RE) & $\mathrm{I}(1)$ & $\mathrm{I}(0)^{* *}$ & $2008: 6,2008: 11$ & All \\
Czech Rep. (SE) & $\mathrm{I}(1)$ & $\mathrm{I}(1)$ & $\mathrm{I}(1)$ & $2001: 4-2005: 10$ \\
\hline Croatia (RE) & $\mathrm{I}(0)^{* *}$ & $\mathrm{I}(1)$ & $2003: 12,2004: 5$ & All \\
Croatia (SE) & $\mathrm{I}(0)^{* *}$ & $\mathrm{I}(0)^{*}$ & $2007: 5,2009: 7$ & $2011: 8-2013: 10$ \\
\hline Hungary (RE) & $\mathrm{I}(0)^{* *}$ & $\mathrm{I}(1)$ & $2002: 12,2003: 5$ & All \\
Hungary (SE) & $\mathrm{I}(1)$ & $\mathrm{I}(1)$ & $\mathrm{I}(1)$ & $2003: 2-2007: 2$ \\
\hline Poland (RE) & $\mathrm{I}(0)^{*}$ & $\mathrm{I}(0)^{* *}$ & $2008: 8,2009: 1$ & All \\
Poland (SE) & $\mathrm{I}(1)$ & $\mathrm{I}(1)$ & $2000: 9,2001: 8$ & $\mathrm{I}(1)$ \\
\hline Romania (RE) & $\mathrm{I}(1)$ & $\mathrm{I}(0)^{* *}$ & $2000: 8,2001: 3$ & All \\
Romania (SE) & $\mathrm{I}(1)$ & $\mathrm{I}(1)$ & $2000: 8,2001: 1$ & $\mathrm{I}(1)$ \\
\hline
\end{tabular}

${ }^{a}$ The crisis sample comprises the period 2008:1-2013:12.

Notes: The symbols $* *$ and $*$ denote rejection of the null of unit root at the $5 \%$ and $10 \%$ significance levels, respectively. 
The results of the $\mathrm{Ng}$ and Perron (2001) test are provided for the whole sample period and for the crisis sample starting in 2008:1. The deviation variable $d U I P$ is stationary when expectations are rational except for the Czech Republic and Romania. For these two countries, however, the deviation variable becomes stationary when the sample is restricted to the crisis sample. The deviation is, except for Croatia, non-stationary when expectations are static and this holds irrespective of the choice of sample.

The dynamic processes of exchange rates and interest rates may change over the sample period as structural change, the global financial crisis and other factors change (Brunnermeier et al. (2008), Hoffmann (2012)). When introducing the possibility of structural breaks in the drift with the LS test, we find evidence in favour of stationarity and the UIP hypothesis in almost all cases, the exceptions being the Czech Republic and Hungary for the static expectations definition.

When allowing for changes in the order of integration with the LKT test, we consistently find support for the UIP hypothesis when the rational expectations definition is used. When the assumption of static expectations is used, the deviation from UIP has a unit root for Poland and Romania throughout the sample, whereas there are short intervals of stationarity for the Czech Republic, Croatia and Hungary. The conclusion from the LKT test is that deviations from UIP are short-lived when expectations are rational, but generally persistent if expectations are static.

The overall lesson from Table 2 is that the deviation from UIP is generally not persistent expectations are rational, but may be so when expectations are static in which case the deviation from UIP is simply the interest rate differential. The results are broadly consistent with the depiction of the two processes in Figure 1. When expectations are rational, the deviations from UIP become very "spiky" reflecting the very large exchange rate changes, and this is consistent with little persistence for most of the countries. When expectations are static, the deviations from UIP become "smoother" and more persistent.

In order to get more detailed information on the evolution of the degree of persistence during the sample period, we present the results of the Bai and Perron (2003) method. First, the number of breaks is obtained for each country and each specification of expectations. Table 3 shows the results of this test, for a maximum of two breaks. To decide the number of breaks, we include the BIC, the LWZ and the F-tests. It is noticeable that we generally cannot find changes in the persistence when the expectations are assumed to be rational (RE). The only exception is Hungary with rational expectations (RE), in which case two structural breaks are found. With the SE definition, the test indicates the existence of two breaks. These results are broadly in line 
with the results in Table 2; as with the LKT test, there is no evidence of breaks with the RE definition, however, two breaks are found for the SE definition.

Table 3: Bai and Perron (2003) breaks determination

\begin{tabular}{|c|c|c|c|c|c|c|}
\hline & Breaks $(k)$ & $\mathrm{BIC}$ & LWZ & $\mathrm{F}(k \mid 0)$ & $\mathrm{F}(k \mid k-1)$ & Decision \\
\hline \multirow{3}{*}{ Croatia (RE) } & 0 & -0.03 & 0.03 & - & - & \multirow{3}{*}{0} \\
\hline & 1 & -0.04 & 0.08 & 6.57 & 6.57 & \\
\hline & 2 & -0.02 & 0.16 & 5.05 & 3.35 & \\
\hline \multirow{3}{*}{ Croatia (SE) } & 0 & -3.88 & -3.81 & - & - & \multirow{3}{*}{2} \\
\hline & 1 & -4.11 & -3.96 & $18.61 * *$ & $18.61 * *$ & \\
\hline & 2 & -4.24 & -4.01 & $16.94 * *$ & $11.35^{* *}$ & \\
\hline \multirow{3}{*}{ Czech Rep. (RE) } & 0 & 1.07 & 1.13 & - & - & \multirow{3}{*}{0} \\
\hline & 1 & 1.08 & 1.20 & 4.28 & 4.28 & \\
\hline & 2 & 1.06 & 1.23 & 5.96 & 7.35 & \\
\hline \multirow{3}{*}{ Czech Rep. (SE) } & 0 & -8.19 & -8.13 & - & - & \multirow{3}{*}{2} \\
\hline & 1 & -8.19 & -8.07 & 5.33 & 5.33 & \\
\hline & 2 & -8.35 & -8.17 & $14.19 * *$ & $21.83 * *$ & \\
\hline \multirow{3}{*}{ Hungary (RE) } & 0 & 4.10 & 4.15 & - & - & \multirow{3}{*}{2} \\
\hline & 1 & 4.08 & 4.19 & 7.15 & 7.15 & \\
\hline & 2 & 3.85 & 4.03 & $19.38 * *$ & $29.39 * *$ & \\
\hline \multirow{3}{*}{ Hungary (SE) } & 0 & -5.88 & -5.82 & - & - & \multirow{3}{*}{2} \\
\hline & 1 & -5.85 & -5.73 & 2.19 & 2.19 & \\
\hline & 2 & -6.05 & -5.88 & $14.85^{* *}$ & $26.89 * *$ & \\
\hline \multirow{3}{*}{ Poland (RE) } & 0 & 2.03 & 2.09 & - & - & \multirow{3}{*}{0} \\
\hline & 1 & 2.06 & 2.18 & 2.70 & 2.70 & \\
\hline & 2 & 2.00 & 2.17 & 7.20 & 11.39 & \\
\hline \multirow{3}{*}{ Poland (SE) } & 0 & -6.50 & -6.44 & - & - & \multirow{3}{*}{2} \\
\hline & 1 & -6.67 & -6.55 & $22.61 * *$ & $22.61 * *$ & \\
\hline & 2 & -6.97 & -6.80 & $36.00 * *$ & $39.79 * *$ & \\
\hline \multirow{3}{*}{ Romania (RE) } & 0 & 1.70 & 1.76 & - & - & \multirow{3}{*}{0} \\
\hline & 1 & 1.65 & 1.77 & 10.60 & 10.60 & \\
\hline & 2 & 1.66 & 1.83 & 7.70 & 4.40 & \\
\hline \multirow{3}{*}{ Romania (SE) } & 0 & -0.65 & -0.59 & - & - & \multirow{3}{*}{2} \\
\hline & 1 & -0.86 & -0.74 & $27.76^{* *}$ & $27.76 * *$ & \\
\hline & 2 & -0.91 & -0.73 & $20.07 * *$ & 9.73 & \\
\hline
\end{tabular}

Note: The minimum value for each of the criteria BIC and LWZ is shown in bold. Superscript ** denotes rejection of the null at the $5 \%$ significance level.

Second, after the selection of the number of breaks in Table 3, we estimate the constant and the autoregressive parameter to assess the degree of persistence for each of the partitions of the sample in an Augmented Dickey Fuller type regression: 


$$
\begin{aligned}
\Delta d U I P_{t} & =\gamma_{1} I\left(t<T_{1}\right)+\alpha_{1} I\left(t<T_{1}\right) d U I P_{t-1} \\
& +\gamma_{2} I\left(T_{1} \leq t<T_{2}\right)+\alpha_{2} I\left(T_{1} \leq t<T_{2}\right) d U I P_{t-1} \\
& +\gamma_{3} I\left(t \geq T_{2}\right)+\alpha_{3} I\left(t \geq T_{2}\right) d U I P_{t-1} \\
& +\sum_{i=1}^{p} \beta_{1} \Delta d U I P_{t-i}+\varepsilon_{t}
\end{aligned}
$$

The indicator function $I($.) takes the value one when the condition in the bracket holds. The specification in (7) is the empirical version of eq. (6).

The results are shown in Table 4 . We focus on the results for static expectations where the deviation from UIP is simply the interest rate differential. For Croatia and the Czech Republic the breaks appear to be related to the outbreak of the global financial crisis. Interestingly, the estimate of the autoregressive parameter is positive for Croatia at the height of the crisis 2008:8-

\begin{tabular}{|c|c|c|c|c|c|}
\hline & $\begin{array}{l}\gamma_{1} \\
\alpha_{1}\end{array}$ & $T_{1}$ & $\begin{array}{l}\gamma_{2} \\
\alpha_{2}\end{array}$ & $T_{2}$ & $\begin{array}{l}\gamma_{3} \\
\alpha_{3}\end{array}$ \\
\hline Croatia (SE) & $\begin{array}{r}0.036 \\
-0.395\end{array}$ & 2008:8 & $\begin{array}{l}0.030 \\
0.530\end{array}$ & 2009:2 & $\begin{array}{r}0.023 \\
-0.300\end{array}$ \\
\hline Czech Rep. (SE) & $\begin{array}{l}-0.002 \\
-0.006 \\
\end{array}$ & 2008:9 & $\begin{array}{r}0.041 \\
-0.455 \\
\end{array}$ & 2009:10 & $\begin{array}{r}0.000 \\
-0.099 \\
\end{array}$ \\
\hline Hungary (RE) & $\begin{array}{l}-1.345 \\
-0.320\end{array}$ & 2002:12 & $\begin{array}{l}17.365 \\
-1.410 \\
\end{array}$ & 2003:6 & $\begin{array}{l}-0.596 \\
-0.621\end{array}$ \\
\hline Hungary (SE) & $\begin{array}{r}0.023 \\
-0.060\end{array}$ & 2003:5 & $\begin{array}{r}0.656 \\
-0.948\end{array}$ & 2003:11 & $\begin{array}{r}0.010 \\
-0.035\end{array}$ \\
\hline Poland (SE) & $\begin{array}{r}0.255 \\
-0.259 \\
\end{array}$ & 1999:10 & $\begin{array}{r}1.185 \\
-0.976 \\
\end{array}$ & 2001:1 & $\begin{array}{r}0.011 \\
-0.057 \\
\end{array}$ \\
\hline Romania (SE) & $\begin{array}{r}7.509 \\
-0.764\end{array}$ & 1999:8 & $\begin{array}{r}6.827 \\
-1.223\end{array}$ & 2000:2 & $\begin{array}{r}0.038 \\
-0.061\end{array}$ \\
\hline
\end{tabular}
$2009: 2$, indicating that there is no dampening of the interest rate differential in this period.

Table 4: Estimation of the broken equations

Note: $T_{1}$ indicates the month of the first time break, $T_{2}$ indicates the month of the second time break.

For Hungary, Poland and Romania the breaks are concentrated at the beginning of the sample in the late 1990s and early 2000s. This was a period of rapid convergence of interest rates as witnessed by numerically large estimates of the autoregressive parameters at the early partitions of the sample (see also Figure 1). The results also indicate that the interest rate differential become less stationary, i.e. there is less evidence in favour of the UIP hypothesis, after the second break. 


\section{Final comments}

The hypothesis of uncovered interest parity posits that the expected returns of investments in assets that are denominated in different currencies but otherwise similar should be equal. This paper examines the empirical validity of this hypothesis using data from five CEE countries for the period 19992013. The five countries, Croatia, the Czech Republic, Hungary, Poland and Romania, are among the largest economies in Central and Eastern Europe and all operated floating exchange rate regimes during the sample period.

The empirical investigation analyses the time series properties of the deviation from uncovered interest parity for investment with a horizon of one month. A persistent deviation would suggest that carry trades would be expected to be profitable, while this would not be the case if the deviation is stationary. Two important innovations are introduced in this paper. First, we consider two different assumptions about the formation of expectations, i.e. rational expectations and static expectations. Second, we allow for structural breaks so as to analyse the evolution of persistence of shocks after and before some endogenously determined dates.

A number of interesting results come out of the empirical analyses. When expectations are assumed to be forward-looking or rational, we find for the five CEE countries that there are not persistent deviations from uncovered interest parity, except a possible constant term. This means that an investor cannot use a deviation from uncovered interest parity as an indication that the deviation will persistent the following month. In other words, an investor should not expect to earn a greater risk-adjusted return from investment in assets denominated in one or the other currency.

When expectations are assumed to static, the deviation from uncovered interest parity is found to exhibit a unit root for at least part of the time sample for all five countries. There seem, however, to be structural breaks in the unit processes either at the beginning of the sample or during the global financial crisis due to disturbance. The beginning of the sample exhibits interest rate convergence for several of the CEE countries, while the period around the global financial crisis saw very substantial disturbance of interest and exchange markets in the sample countries. The lack of empirical support for the UIP hypothesis in this case may suggest the presence of arbitrage possibilities for an investor with static expectations. The observed presence of carry trade may thus be tied to investors having static or non-rational expectations.

The overall conclusion from this study is that expectations are of prime importance for the results when the UIP hypothesis is tested empirically. In the sample of CEE countries used in this paper, the assumption of forward- 
looking or rational expectations implies that the hypothesis of UIP cannot be rejected, while the assumption of static expectations generally means that the UIP hypothesis cannot be upheld in most parts of the sample period. These results clearly underscore the importance of the assumptions regarding the expectation when the UIP hypothesis is tested, but also suggest the pertinence of studies of the formation of expectations in foreign exchange and interest markets. 


\section{References}

ALEXIUS, A. (2001): Uncovered interest parity revisited. Review of International Economics, Vol. 9, No. 3, pp. 505-517.

ALPER, C. E., O. P. ARDIC, AND S. FENDOGLU (2009): The economics of uncovered interest parity condition for emerging markets: A survey. Journal of Economic Surveys, Vol. 23, No. 1, pp. 115-138.

BAI, J., AND P. PERRON (2003): Computation and analysis of multiple structural change models. Journal of Applied Econometrics, Vol. 18, No. 1, pp. 1-22.

BAILLIE, R. T., AND D. CHO (2014): Time variation in the standard forward premium regression: some new models and tests. Journal of Empirical Finance, Vol. 29, pp. 52-63.

BANSAL, R., AND M. DAHLQUIST (2000): The forward premium puzzle: different tales from developed and emerging economies. Journal of International Economics, Vol. 51, No. 1, pp. 115-144.

BOOTH, P., AND D. LONGWORTH (1986): Foreign exchange market efficiency tests: implications of recent empirical findings. Journal of International Money and Finance, Vol. 5, No. 2, pp. 135-152.

BRASILI, A., AND B. SITZIA (2003): Risk related non linearities in exchange rates: evidence from a panel of Central and Eastern European Countries. Open Economies Review, Vol. 14, No. 2, pp. 135-155.

BRUNNERMEIER, M. K., S. NAGEL, AND L. H. PEDERSEN (2008): Carry trades and currency crashes. NBER Working Paper, No. w14473, National Bureau of Economic Research.

BRZOZA-BRZEZINA, M., T. CHMIELEWSKI, AND J. NIEDŹWIEDZIŃSKA (2010): Substitution between domestic and foreign currency loans in Central Europe. Do central banks matter?. ECB Working Paper Series, No. 1187, European Central Bank.

CHINN, M. D., AND G. MEREDITH (2004): Monetary policy and longhorizon uncovered interest parity. IMF Staff Papers, Vol. 51, No. 3, pp. 409-430.

DE GRAUWE, P. (2014): Exchange Rates and Global Financial Policies. World Scientific Publishing.

ENGEL, C. (1996): The forward discount anomaly and the risk premium: A survey of recent evidence. Journal of Empirical Finance, Vol. 3, No. 2, pp. 123-192. 
ENGEL, C. (2014): Exchange rates and interest parity. In G. Gopinath, E. Helpman, and K. Rogoff (eds.): Handbook of International Economics. Vol. 4, Ch. 8, pp. 453-522.

FELCSER, D., AND B. VONNÁK (2014): Carry trade, uncovered interest parity and monetary policy. MNB Working Paper, No. 2014/3, Magyar Nemzeti Bank.

FILIPOZZI, F., AND K. STAEHR (2012): Uncovered interest parity in Central and Eastern Europe: Convergence and the global financial Chrisis. Discussions on Estonian Economic Policy: Theory and Practice of Economic Policy, Vol. 20, No. 1, pp. 58-82.

FROOT, K. A., AND R. H. THALER (1990): Anomalies of foreign exchange. Journal of Economic Perspectives, Vol. 4, No. 3, pp. 179-192.

GOH, S. K., G. C. LIM, AND N. OLEKALNS (2006): Deviations from uncovered interest parity in Malaysia. Applied Financial Economics, Vol. 16, No. 10, pp. 745-759.

HOFFMANN, A. (2012): Determinants of carry trades in Central and Eastern Europe. Applied Financial Economics, Vol. 22, Nos. 16-18, pp. 14791490.

HOLTEMÖLLER, O. (2005): Uncovered interest rate parity and analysis of monetary convergence of potential EMU accession countries. International Economics and Economic Policy, Vol. 2, No. 1, pp. 33-63.

JEVCAK, A., R. SETZER, AND M. SUARDI (2010): Determinants of capital flows to the New EU Member States before and during the financial Chrisis. European Economy. Economic Papers, No. 425.

JIANG, C., X. L. LI, H. L. CHANG, AND C. W. SU (2013): Uncovered interest parity and risk premium convergence in Central and Eastern European countries. Economic Modelling, Vol. 33, pp. 204-208.

LEE, J., AND M. C. STRAZICICH (2003): Minimum LM unit root test with two structural reaks. Review of Economics and Statistics, Vol. 85, No. 4, pp. 1082-1089.

LEVI, M. D. (2005): International Finance. Routledge.

LEYBOURNE, S., T.-H. KIM, AND A. M. R. TAYLOR (2007): Detecting multiple changes in persistence. Studies in Nonlinear Dynamics and Econometrics, Vol. 11, No. 3, pp. 1-34.

LI, D., A. GHOSHRAY, AND B. MORLEY (2013): An empirical study of nonlinear adjustment in the UIP model using a smooth transition regression model. International Review of Financial Analysis, Vol. 30, pp. 109-120. 
LIU J, S. WU, AND J. V. ZIDEK (1997): On segmented multivariate regressions. Statistica Sinica, Vol. 7, pp. 497-525.

LOTHIAN, J. R., AND L. WU (2011): Uncovered interest-rate parity over the past two centuries. Journal of International Money and Finance, Vol. 30, No. 3, pp. 448-473.

MEESE, R. A., AND K. ROGOFF (1983): Empirical exchange rate models of the seventies. Do they fit out of sample?. Journal of International Economics, Vol. 14, No. 1-2, pp. 3-24.

MEHL, A., AND L. CAPPIELLO (2007): Uncovered interest parity at distant horizons. Evidence on emerging economies and nonlinearities. ECB Working Paper, No. 801, European Central Bank.

NG, S., AND P. PERRON (2001): Lag selection and the construction of unit root tests with good size and power. Econometrica, Vol. 69, No. 6, pp. 1519-1554.

ROSENBERG, C. B., AND M. TIRPAK (2009): Determinants of foreign currency borrowing in the new member states of the EU. Finance $a$ uver - Czech Journal of Economics and Finance, Vol. 59, No. 3, pp. 216-228.

SARMIDI, T., AND N. H. M. SALLEH (2011): Time horizon and uncovered interest parity in emerging economies. Asian Academy of Management Journal, Vol. 16, No. 2, pp. 107-130.

TER ELLEN, S., W. F. VERSCHOOR, AND R. C. ZWINKELS (2013): Dynamic expectation formation in the foreign exchange market. Journal of International Money and Finance, Vol. 37, pp. 75-97.

TRIANDAFIL, C. M., AND C. RICHTER (2012): Testing the UIP theory in the CEE countries. INFER Working Paper, No. 2012.8, International Network for Economic Research. 
Working Papers of Eesti Pank 2015

No 1

Lenno Uusküla. Firm Turnover and Inflation Dynamics

No 2

Andres Kuusk, Karsten Staehr, Uku Varblane. Sectoral Change and Labour Productivity Growth during Boom, Bust and Recovery in Central and Eastern Europe

No 3

Kadri Männasoo, Jaanika Meriküll. The Impact of Firm Financing Constraints on R\&D over the Business Cycle 